\title{
Pore-scale investigation of selective plugging mechanism in immiscible two-phase flow using phase-field method
}

\author{
Ehsan Sabooniha ${ }^{1}$, Mohammad-Reza Rokhforouz $^{2, *}$, and Shahab Ayatollahi ${ }^{2}$ \\ ${ }^{1}$ Department of Petroleum Engineering, Amirkabir University of Technology, Tehran, Iran \\ ${ }^{2}$ Department of Chemical and Petroleum Engineering, Sharif University of Technology, Tehran, Iran
}

Received: 16 May 2019 / Accepted: 18 September 2019

\begin{abstract}
Biotechnology has had a major effect on improving crude oil displacement to increase petroleum production. The role of biopolymers and bio cells for selective plugging of production zones through biofilm formation has been defined. The ability of microorganisms to improve the volumetric sweep efficiency and increase oil recovery by plugging off high-permeability layers and diverting injection fluid to lower-permeability was studied through experimental tests followed by multiple simulations. The main goal of this research was to examine the selective plugging effect of hydrophobic bacteria cell on secondary oil recovery performance. In the experimental section, water and aqua solution of purified Acinetobacter strain RAG-1 were injected into an oil-saturated heterogeneous micromodel porous media. Pure water injection could expel oil by $41 \%$, while bacterial solution injection resulted in higher oil recovery efficiency; i.e., $59 \%$. In the simulation section, a smaller part of the heterogeneous geometry was employed as a computational domain. A numerical model was developed using coupled Cahn-Hilliard phase-field method and Navier-Stokes equations, solved by a finite element solver. In the non-plugging model, approximately $50 \%$ of the matrix oil is recovered through water injection. Seven different models, which have different plugging distributions, were constructed to evaluate the influences of selective plugging mechanism on the flow patterns. Each plugging module represents a physical phenomenon which can resist the displacing phase flow in pores, throats, and walls during Microbial-Enhanced Oil Recovery (MEOR). After plugging of the main diameter route, displacing phase inevitably exit from sidelong routes located on the top and bottom of the matrix. Our results indicate that the number of plugs occurring in the medium could significantly affect the breakthrough time. It was also observed that increasing the number of plugging modules may not necessarily lead to higher ultimate oil recovery. Furthermore, it was shown that adjacent plugs to the inlet caused flow patterns similar to the non-plugging model, and higher oil recovery factor than the models with farther plugs from the inlet. The obtained results illustrated that the fluids distribution at the pore-scale and the ultimate oil recovery are strongly dependent on the plugging distribution.
\end{abstract}

\section{Introduction}

When primary oil recovery processes no longer produce efficient oil due to natural depletion of the reservoir, secondary or tertiary oil extraction is adopted [1-3]. One of the simplest and economical secondary extraction mechanisms is water flooding, where water is injected into a reservoir. Typically about $20-40 \%$ of Original Oil In Place (OOIP) can be recovered by conventional methods [4]. To increase the ultimate oil recovery, it is crucial to understand the simultaneous impact of multiple factors, including wettability, fluid viscosities, capillarity, and medium heterogeneities [5]. High-permeability and fractured reservoirs generally have an early water breakthrough time, which adversely

\footnotetext{
* Corresponding author: mrokhforouz92@gmail.com
}

affects their recovery performance. It is known that the selective plugging of permeable routes may postpone the breakthrough time and lead to higher oil recovery. Also using additives such as chemical solvents and bacteria in Enhanced Oil Recovery (EOR) process have been increased during the last years because of their potential in Interfacial Tension (IFT) reduction and wettability alteration [6]. These materials can also produce hydrophobic biomasses and long-chain molecules through which high permeability pathways are plugged. Consequently, a later water breakthrough time and higher oil production can be expected [7].

Microbial-Enhanced Oil Recovery (MEOR), which is regarded as a tertiary method to increase oil recovery, uses different microorganisms to extract trapped oil from the reservoirs [8, 9]. Several mechanisms are proposed to explain the incremental oil recovery associated with 
MEOR, among which are the reduction in the oil-water IFT and changes in the wettability of the system and selective plugging mechanism [10-13]. Numerous experimental and numerical studies have been conducted to understand the impact of wettability alteration and IFT reduction [14-24]. Kowalewski et al. [25] showed that the bacterial growth could both reduce IFT and alter the wettability state toward less oil-wet conditions. They also conducted a subsequent simulation study and demonstrated that a change in wettability toward water-wet behavior and IFT reduction could reproduce the increased oil recovery. Darvishi et al. [26] studied the potential of the bacterial consortium of Enterobacter cloacae and Pseudomonas sp. It was shown that under simulated reservoir conditions, IFT reduction, gas production, and wettability alteration were the main mechanisms for EOR. It was also found that the biosurfactant production is the most effective factor in IFT reduction and wettability alteration. Karimi et al. [27] conducted some experiments using an Enterobacter cloacae strain with different substrates at fresh conditions or aged in crude oil to simulate various wetting conditions. They found out that the surface wettability could vary from water-wet to oil-wet condition. They also illustrated that bacterial adhesion and biofilm formation are the dominant mechanisms of wettability alteration. Chisholm et al. [28] flooded in situ microorganism samples from a well in Oklahoma into core samples and showed that incremental oil recovery associated with each nutrient treatment is the oil produced by the release of in situ gas pressure. This in situ gas is produced during incubation of core with nutrients plus the oil. Florez et al. [29] proposed an exploratory methodology to reproduce both physical (petrophysical) and chemical (mineralogy) rock characteristics, and behavior of carbonates in oil and gas reservoirs. This alternative approach would significantly decrease the difficulty of obtaining reservoir plug samples. The low-cost samples could be utilized to study different mechanism of MEOR.

Earlier studies demonstrated that the plugging mechanism can be the most important mechanism in oil recovery [30]. In the following studies, it was dedicated that the hydrophobic bacteria cells and participated bioproducts of bacteria-oil reactions are the plugging factors in most cases [31]. Plugging is formed in the shape of a thin layer biofilm or mud cake which can partially or completely block flow pathways [32]. Kalish et al. [33] investigated the plugging potential of bacteria cells separately in core flooding procedure. They observed that the rod-shaped cells were more efficient plugging agents than small aggregates of spherical cells, which in turn were more efficient than singly-dispersed cells. It was also reported that for cores which are partially plugged, Darcy's law is not applicable because increases in injection pressure are not linearly related to flow rate. Suthar et al. [34] studied selective plugging strategy of Bacillus licheniformis TT33 and showed that the produced exopolymeric substances blocked the high permeability zones of the porous media; thus, the fluids could flow through the low permeability zones led to an increase in the oil recovery. Stewart and Scott Fogler [35] conducted a series of micromodel tests to understand biomass plugging of porous media. They studied Leuconostoc mesenteroides plugging effect under nutrient-rich conditions. They observed that as the nutrient flows through the micromodel, the initial biomass plugging occurred at the nutrient-inoculum interface due to growth in the larger pores and throats. As the growth proceeded, biomass filled and closed these pores/throats until the only isolated grouping of pores/throats with smaller radii remained empty. They also found out that breakthrough channel locations would change due to redistribution of the nutrient flow and changes in the flow rate.

Two dimensional flow channels which are known as micromodels are one of the most efficient tools for evaluating different mechanisms during fluid flow in porous media. [36-38]. Micro-fabricated physical devices of porous media (i.e., micromodels) have been widely used to study EOR process and investigate different fluid flow mechanisms [36]. Various microfabrication methods have been used in the fabrication of microfluidic devices for EOR process study, including optical lithography, chemical etching, plasma etching, and stereolithography. These fabrication methods usually involved a complicated fabrication procedure with highly sophisticated instruments, which formed a technical barrier for the researchers in energy fields to benefit from microfluidics technology. In order to lower the barrier of visualization and cost in EOR process, Fan et al. [39] introduced a low-cost PMMA-based microfluidics device to mimic the porous media inside the sandstone. They illustrated that the PMMA-based microfluidic devices provided a simple and low-cost visualization tool for the study of EOR process.

Numerical simulation is an applicable technique to evaluate the experimental results. They can eliminate the considerable limitation of experiments and lead to a better understanding of the oil recovery mechanism [40, 41]. Numerical studies of governing mechanisms of two-phase flow in porous media have been conducted by many researchers [42, 43]. Pore-network modeling [44-46], smoothed particles hydrodynamics $[47,48]$, Lattice Boltzmann (LB) [49, 50], quasi-static [51, 52] and direct numerical simulation approaches based on interface capturing techniques such as Volume of Fluid (VoF) [46, 53, 54], level set [55] and phase-field [56-59] are the most common approaches which have been developed to simulate the multiphase flow in porous media. A detailed study of advantages and drawbacks of these techniques can be found elsewhere [60]. Direct numerical simulations are considered as a favorable approach to simulate two-phase flow [53,60]. Phase-field method has been proven in different reported studies to capture physical phenomena in fluid displacements through complex pore geometries $[5,17,61-63]$

In this paper, flow and transport in porous media were modeled at the pore-scale using Navier-Stokes-based solver. It should be stated that the effect of bacteria in two-phase flows in porous media was not considered in the numerical model. In the second section, experimental setup and procedure for water and bacteria solution injection into a heterogeneous micromodel is presented. In the third section, numerical scheme along with governing equations are clarified. Cahn-Hilliard phase-field method coupled with Navier-Stokes and continuity equations are employed for 
studying different scenarios for selective plugging mechanism $[61,64]$. In the results and discussion section, the obtained results of flooding experiment and simulated model are given and compared. Different bacteria solution injection scenarios are discussed in detail, and the influences of the selective plugging mechanism on flow pattern were described.

\section{Experimental study}

\subsection{Materials and methods}

The crude oil used in this experiment was extracted from Kupal oil field located in the south of Iran. The viscosity and density of this oil were measured $44 \mathrm{cP}$ and $908 \mathrm{~kg} / \mathrm{m}^{3}$, respectively. Moreover, water used as the displacing phase had the viscosity and density of $1.0 \mathrm{cP}$ and $1010 \mathrm{~kg} / \mathrm{m}^{3}$, respectively. Afterward, spherical-shape Acinetobacter strain RAG-1 was mixed with distilled water and was also utilized as the displacing phase. Acinetobacter bacteria cell, which has hydrophobic surfaces, is efficient in the investigation of the selective plugging mechanism. It can also act as bridging organisms and contribute to solid-liquid separation in reaction with organic materials such as the crude oil [65].

\subsection{Experimental setup}

A visual flooding experiment was designed to study the displacement mechanism and validate the numerical model. Water-bacteria cell solution with limited nutrient was employed to study the secondary flooding in the heterogeneous micromodel saturated with the crude oil and connate water. For this purpose, active bacteria cell was grown in the solid Luria-Bertani (LB) medium, then it was added to LB fluidic medium. After proper fertilization, additional active produced cells were centrifuged and isolated from the solution. This procedure was then repeated for six times to obtain the remaining cells from the solution. In the next step, the isolated cells were added to the distilled water in order to initiate the injection process into the micromodel. The measured Optical Density (OD) of the bacteria solution was about 1 OD. A dolomite pattern was implemented as porous media in heterogeneous micromodel (Fig. 1). Dry etching (laser beam) and wet chemical etching (HF acid solution) approaches were used to print the pattern on the float glass and obtain controlled pore and throat sizes. The physical properties of the micromodel and experimental conditions are given in Table 1 . The inlet and outlet ports of the micromodel were then drilled in a separate glass. Finally, the etched plate was fused to the drilled plate using controlled temperature furnace, and the micromodel porous media was attained.

Matlab image processing toolbox was employed to calculate the porosity of the micromodel, the ratio of void space volume to the bulk volume of the domain. The micromodel setup sketch comprises horizontal glass micromodel, micromodel holder, pressure transmitter, injection pump, back light system, data logger, and computer-based motion

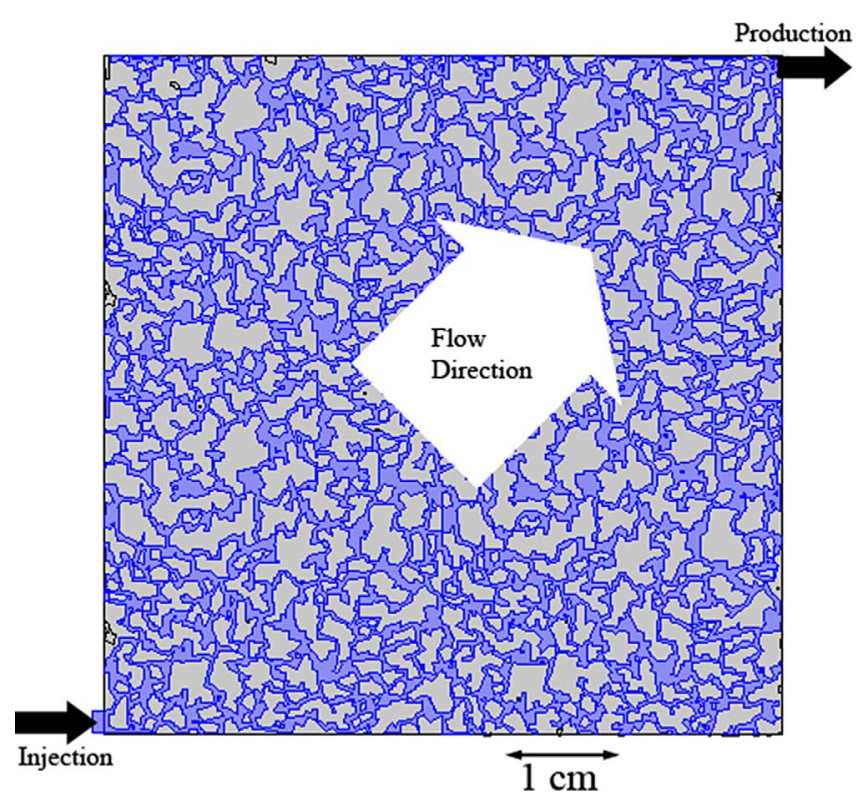

Fig. 1. Micromodel scheme implemented in the experiment and simulations. Pores and grains are discretized by blue and gray areas. Inlet and outlet are shown with arrows.

Table 1. Properties of fluids and the matrix block along with the experimental condition.

\begin{tabular}{lcc}
\hline Parameters & Symbol & Value \\
\hline Oil density $\left(\mathrm{kg} / \mathrm{m}^{3}\right)$ & $\rho_{0}$ & 896 \\
Oil viscosity $(\mathrm{Pa} \cdot \mathrm{s})$ & $\mu_{0}$ & 0.044 \\
Water density $\left(\mathrm{kg} / \mathrm{m}^{3}\right)$ & $\rho_{w}$ & 1000 \\
Water viscosity $(\mathrm{Pa} \cdot \mathrm{s})$ & $\mu_{\mathrm{w}}$ & 0.001 \\
Initial temperature $\left({ }^{\circ} \mathrm{C}\right)$ & $T$ & 20 \\
Differential pressure $(\mathrm{Pa})$ & $\Delta P$ & 1723.689 \\
Flow rate $(\mathrm{mL} / \mathrm{h})$ & $Q$ & 0.12 \\
Contact angle $(\mathrm{rad})$ & $\theta_{\text {water-oil }}$ & $\pi / 2$ \\
Mean throat sizes $(\mathrm{cm})$ & $R_{\mathrm{t}}$ & 0.015 \\
Mean pore sizes $(\mathrm{cm})$ & $R_{\mathrm{p}}$ & 0.08 \\
Etching thickness $(\mu \mathrm{m})$ & $\varepsilon$ & 138 \\
Porous media volume $(\mathrm{cc})$ & $V$ & 0.25 \\
Permeability $($ Darcy $)$ & $K$ & 4 \\
Water-oil interfacial tension $(\mathrm{mN} / \mathrm{m})$ & $\sigma_{\text {water-oil }}$ & 24 \\
\hline
\end{tabular}

capturing system (as shown in Fig. 2). A ball valve was set at the entrance to manage the fluid flow, and a Rosemount Differential Pressure (DP) transmitter was implemented to measure the injection pressure with a resolution of $0.086 \mathrm{kPa}$. The inlet pressure was equivalent to the total pressure drop in the model, and the outlet pressure was set at atmospheric pressure. The DP was calibrated within the range of 0-344.74 $\mathrm{kPa}$. Differential pressure values were recorded every $2 \mathrm{~s}$ by the data logger system which was 


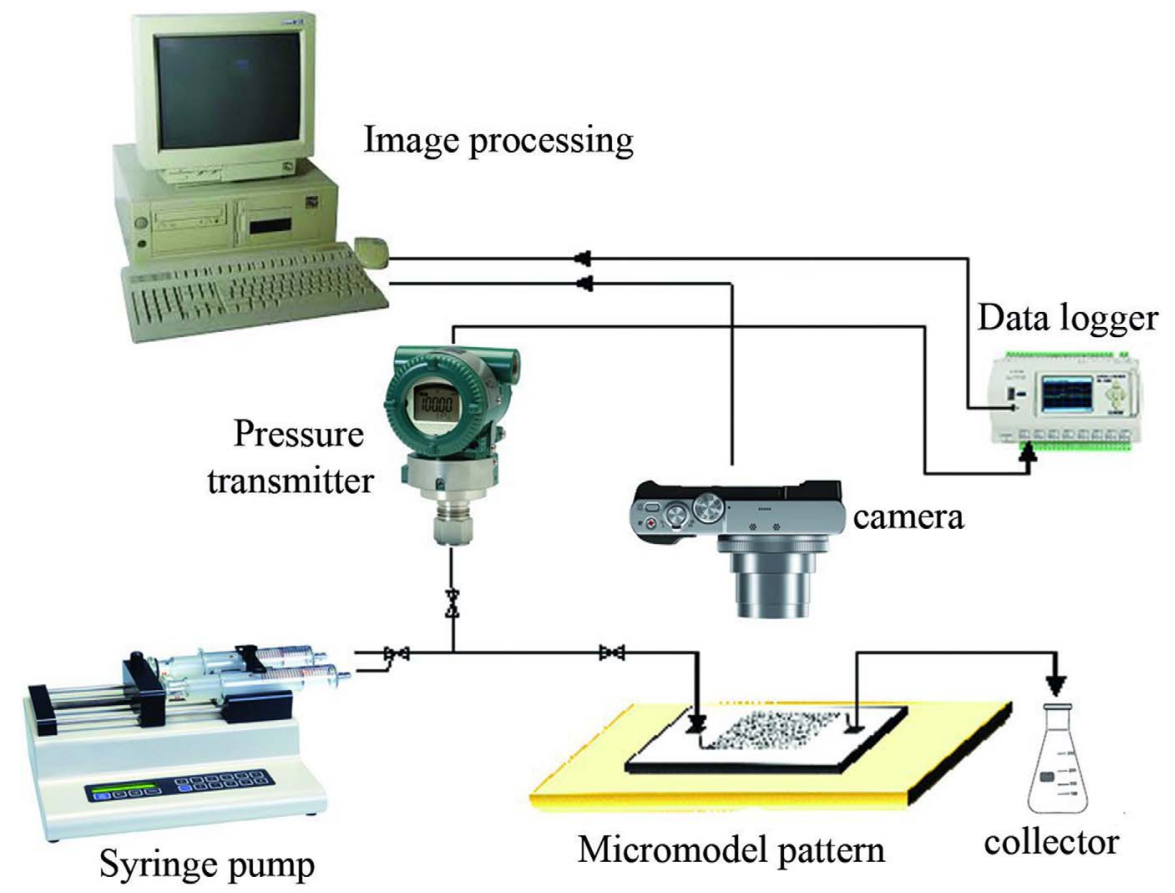

Fig. 2. Experimental setup used for bacteria injection into the $2 \mathrm{D}$ glass micromodel.

connected to the DP via a cable. A Nikon digital camera was used to take images at different steps of the process and capture fluids distribution at different times. To improve the resolution of images, a LED light bulb was used. The fluid injection was conducted with ATS2-60 syringe pump apparatus. It was connected to pneumatic lines which were responsible for carrying the fluid from syringe to the micromodel. In the beginning, the crude oil was injected from the left-bottom side of the medium with a constant injection rate of $0.12 \mathrm{~cm}^{3} / \mathrm{h}$ (which guaranteed laminar flow in our micromodel porous medium). Oil was also produced from the right-top side of the medium. The injection process has proceeded until the micromodel was saturated with crude oil. Then, the bacteria solution was injected into the medium at the same flow rate to displace the oil in place. Injection of the solution was continued until the saturation of the oil and solution reached their steadystate values. The saturation of both phases was obtained using the image processing toolbox. The main objective of this design was to capture the interface of fluids and to measure the bacteria solution and crude oil saturations.

To clean the saturated micromodel, alternate cycles of alcohol, acetone, and toluene were implemented. The medium wettability, in the absence of bacteria, was determined by measuring the contact angle between the oil phase and the micromodel surface calculated from pore-scale images taken by Nikon digital camera. For measuring the wateroil IFT, a pendant drop apparatus was employed. It should be noted that the preliminary water/bacteria solution only contains live bacteria cells and there are no bio-products responsible for IFT reduction and wettability alteration; therefore, the effect of IFT reduction and wettability alteration were eliminated.

\section{Numerical model}

COMSOL Multiphysics [66] software has become a reliable tool for solving two-phase flow problem, which includes interface capturing methods (e.g., phase-field, and level set) $[56,61,63,67]$. Navier-Stokes equations coupled with a diffuse interface method are available in the microfluidics module of the software. Governing equations, computational geometry and numerical scheme are presented here.

\subsection{Phase-field method}

The phase-field method is implemented to solve the twophase problem in the model. It originates from the principle of minimum free energy of an isolated thermal system. Treating the interface as a diffused layer across which the fluid properties change steeply with a phase index $(\Phi)$ as the indicator is the key idea of the method. Phase-field variable varies in the thin diffuse interface region from -1 to 1 and stands uniform in the bulk phases. The free energy density model for a two-phase model is:

$$
F(\phi)=\int_{\Omega}\left[\frac{1}{2} \lambda|\nabla \phi|^{2}+f_{0}(\phi)\right] \mathrm{d} x,
$$

where $\Omega$ is the space in which two fluid components exist. The first term in the integrated right hand side describes surface energy. The second term of integral $f_{0}(\phi)$ stands for bulk energy which is defined based on double-well potential as:

$$
f_{0}(\phi)=\frac{\lambda}{4 \varepsilon^{2}}\left(\phi^{2}-1\right)^{2}
$$


where $\lambda$ is the mixing energy density $(N)$ and $e$ accounts for the thickness of interface. The combination of two parameters forms surface tension through the following equation:

$$
\sigma=\frac{2 \sqrt{2}}{3} \frac{\lambda}{3}
$$

the Cahn-Hilliard equation which describes the convection-diffusion nature of species solves the two-phase flow dynamic in this approach. The equation simulates creation, evolution and dissolution of the interface. Therefore, the Cahn-Hilliard are as follows:

$$
\begin{gathered}
\frac{\partial \phi}{\partial t}+u \cdot \nabla \phi=\nabla \cdot(\gamma \nabla G), \\
\frac{\partial \varphi}{\partial t}+u \cdot \nabla \varphi=\nabla \cdot\left(\frac{\gamma \lambda}{\varepsilon^{2}}\right) \nabla \psi, \\
\psi=-\nabla \cdot \varepsilon^{2} \nabla \varphi+\left(\varphi^{2}-1\right) \varphi,
\end{gathered}
$$

where $\varphi$ represents the phase-field parameter. $\psi$ is auxiliary parameter to decompose fourth-order Cahn-Hilliard equation to the two-order equation, $u$ is the fluid velocity $(\mathrm{m} / \mathrm{s}), \varepsilon$ is the interface thickness $(\mathrm{m}), \gamma$ is the mobility $\left(\frac{\mathrm{m}^{3} \mathrm{~s}}{\mathrm{Kg}}\right)$ and $G$ is the chemical potential $\left(\frac{\mathrm{J}}{\mathrm{m}^{3}}\right)$ defined as:

$$
G=\lambda\left[-\nabla^{2} \phi+\phi\left(\phi^{2}-1\right) / \varepsilon^{2}\right] .
$$

Both density and viscosity of each phases at the interface are functions of phase-field variable and defined based on the following equations:

$$
\rho=\rho_{1}+\left(\rho_{2}-\rho_{1}\right) V_{f 2} \quad \mu=\mu_{1}+\left(\mu_{2}-\mu_{1}\right) V_{f 2},
$$

where subscripts 1 and 2 denote fluid 1 and fluid 2, respectively. $\mathrm{V}_{f}$ is the volume fraction of each phase determined as follows:

$$
V_{f 1}=\frac{1-\varphi}{2} \quad V_{f 2}=\frac{1+\varphi}{2} .
$$

Further information about phase-field method can be found elsewhere [68].

\subsection{Fluid transport dynamics}

Navier-Stokes equations are applied to describe the fluid dynamic motion and account for mass and momentum transport for fluids. The coupled Navier-Stokes-CahnHilliard equations are then as follows:

$$
\begin{aligned}
& \rho \frac{\partial u}{\partial t}+\rho(u \cdot \nabla) u= \\
&-\nabla P+\nabla \cdot\left[\mu\left(\nabla u+(\nabla u)^{T}\right)\right]+G \nabla \varphi, \\
& \quad \nabla \cdot u=0,
\end{aligned}
$$

where $\rho$ is the density $\left(\frac{\mathrm{Kg}}{\mathrm{m}^{3}}\right), \mu$ stands for viscosity $\left(\frac{\mathrm{Ns}}{\mathrm{m}^{2}}\right), P$ is the pressure $(\mathrm{Pa}), u$ is the velocity field $\left(\frac{\mathrm{m}}{\mathrm{s}}\right)$. Primary assumptions are incompressible and immiscible fluid properties with no phase changing occurring, meanwhile, gravity force is neglected due to $2 \mathrm{D}$ horizontal flow. On the solid wall, the following equations are instated as boundary condition in the model:

$$
\begin{gathered}
u=0, \\
n \cdot \nabla=0, \\
\lambda n \cdot \nabla \phi+f_{w}^{\prime}(\phi)=0 .
\end{gathered}
$$

The first equation denotes the no slip condition. The second one accounts for zero diffusive flux and the last one is the natural boundary condition originating from the variation of total free energy. Further details about boundary conditions can be found elsewhere [69, 70].

\subsection{Boundary conditions and numerical scheme}

A smaller part of the employed micromodel porous media in the experiment was used as the computational domain, given computational constraints. The pore size distribution of the model is the same as the experimental pattern. Figure 3a shows the 2D model used for the simulation of selective plugging distribution during oil recovery. Adaptive mesh refinement method was employed to refine grids at the interface as the front moves. This technique was used to achieve numerical accuracy, while maintaining an optimal number of mesh elements. More information about adaptive mesh refinement can be found elsewhere [5]. The discretized domain utilizing adaptive mesh refinement is shown in Figure 3b. Element size $(\mu \mathrm{m})$ distribution with adaptive mesh refinement is depicted in Figure 4. For further studying of the plugging contribution in ultimate oil recovery, some effective throats and directions were numbered as shown in Figure 3c. The oil phase was initially present in the system, and water/bacteria solution was injected from the left-bottom of the model. A pressure difference is imposed on the system to cause the fluid flow. Initial velocity and pressure are set to zero. The boundary condition of solid grains is considered as a wetted wall with specific contact angles $(\theta=\pi / 2)$.

Seven cases of water or bacteria solution injection into an oil-saturated medium are simulated in two dimensional. Case 1 represents the basic no-bacteria water flooding situation. Cases 2-4 include different geometrically modified models with different plugging distributions. Case 4-7 describe in situ bacterial growth and involve gradual changes in matrix geometry. Initial boundary conditions and saturations of all bacterial flooding models are identical to the water flooding model.

\section{Results and discussion}

\subsection{Visual flooding experiment}

The obtained results of bacteria solution injection into an oil-saturated micromodel porous media are presented in Figure 5. Figure 5a shows that the medium is initially 


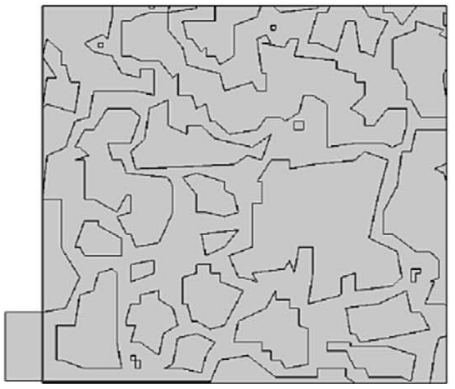

(a)

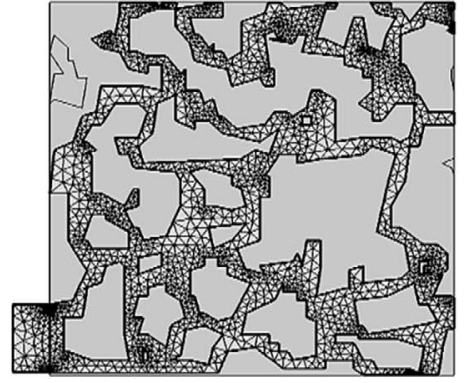

(b)

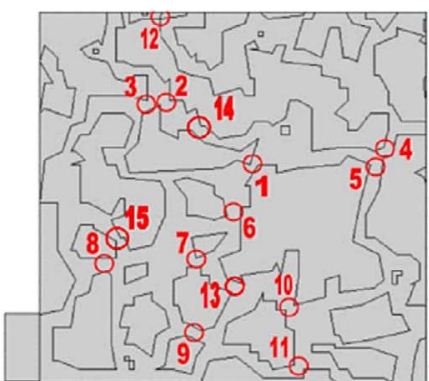

(c)

Fig. 3. (a) Computational domain, (b) discretized domain, and (c) indexing different pores/throats.

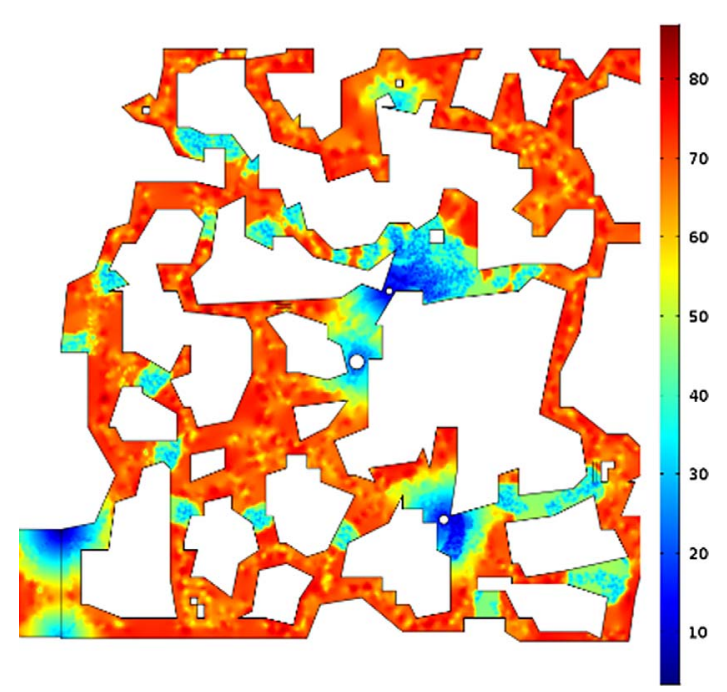

Fig. 4. Element size $(\mu \mathrm{m})$ distribution with adaptive mesh refinement.

saturated with the oil phase (black color) and connate water. Afterward, the bacteria solution is injected from the left-bottom side of the medium with a constant injection rate (Fig. 5b). As can be seen in Figure 5c, bacteria solution sweeps bottom, middle, and upper sides of the micromodel laterally at the early times. At $t_{\mathrm{D}}=0.42$, displacing phase forms a few fingers from the main diagonal pathway of the medium until the water breakthrough happens (Fig. 5d). After stabilization, a portion of the resident oil is trapped mainly in the top and bottom sides of the domain. Figure 6 depicts the same snapshots for water injection. Comparing Figures 5 and 6 enabled us to determine locations of pore plugging, used as the input for the model. Secondary oil recovery factor through bacteria solution injection is compared with that of water injection (see Fig. 7). The dimensionless time is defined as $t_{\mathrm{D}}=$ $t / t_{\text {breakthrough. }}$. The oil recovery factor is defined as the ratio of the total recovered oil to the total reservoir oil. Bacteria solution injection could produce almost $60 \%$ of the matrix oil during the displacement process, while $40 \%$ of the matrix oil was extracted through water flooding. Through having a limited nutrient bacteria solution, it was tried to decrease bio-products creation and minimize the effects of wettability alteration and IFT reduction. Hence, it can be stated that the selective mechanism caused mainly this improvement in oil recovery.

\subsection{Water-oil displacement modeling}

The established numerical model was previously validated in our paper [63]. In the first model (model No 1), distilled water is used as the displacing fluid, and no plugging is added in the geometry. As shown in Figure 8a, initially the micromodel is saturated with the oil phase (red color), and the inlet part is saturated with the water as an initial fluid-fluid interface (blue color), which is needed for numerical stability. Through water invasion from the bottom left corner, the oil phase is produced from the top-right corner of the domain (Fig. 8b). Figures $8 \mathrm{c}$ and $8 \mathrm{~d}$ illustrate that the water progressed by forming three fingers. As shown in Figure $8 \mathrm{e}$, water jumped diagonally through the tortuous pathway which has the least difference between the inlet and outlet. Having an intermediate wetting condition makes the water sweep both the large and small pore bodies. It can be observed that the water cannot displace the oil from the top and bottom side routes, and the water breakthrough time happened. Consequently, the resident oil of those zones gets trapped (Fig. 8f). Pressure and velocity fields at $t_{\mathrm{D}}=0.71$ (corresponding to Fig. 8e) for the model No 1 are presented in Figure 9. As can be seen in Figure 9a, a pressure difference in the matrix can be observed, i.e., capillary pressure, which is a function of IFT, contact angle, and pore radius. The obtained velocity profile shows the main water and oil streamline inside the domain, through which the water breakthrough happened (see Fig. 9b).

There is almost a $10 \%$ difference in the oil recovery between experiment and simulation of water flooding. It comes from the fact that simulations are $2 \mathrm{D}$, while the experiments are $3 \mathrm{D}$. The numerical model does not include the interface curvature in the micromodel thickness direction. Other sources including the boundary conditions at the solid surface, the uncertainty in the physical properties measurements, the confinement effects, and an additional drag force in the micromodel can cause differences between $2 \mathrm{D}$ and $3 \mathrm{D}$ results. 3D geometries may consist of a vug or fracture which is invisible in the 2D images. In addition, some dead-end pore/throats in 2D images can be connected to the main flow channel in the 3D structure. 


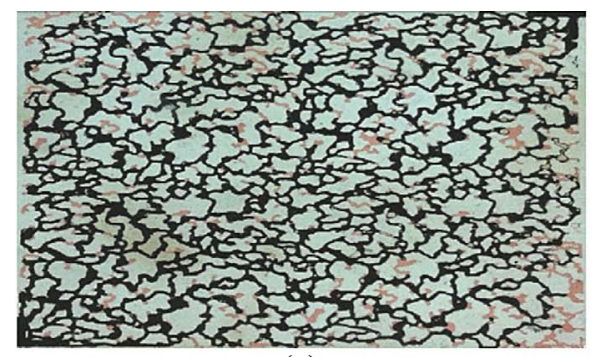

(a)

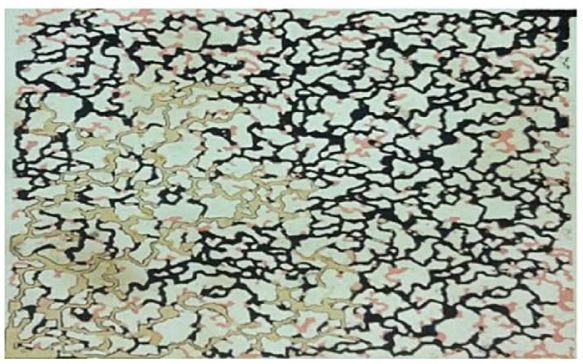

(c)

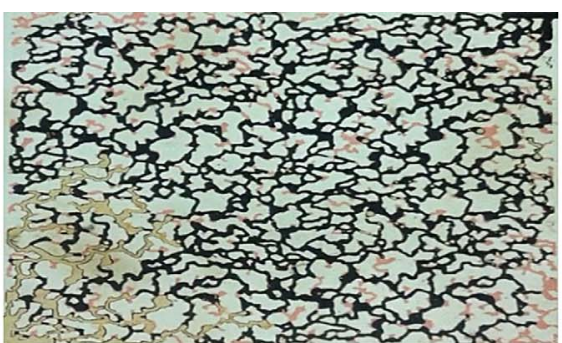

(b)

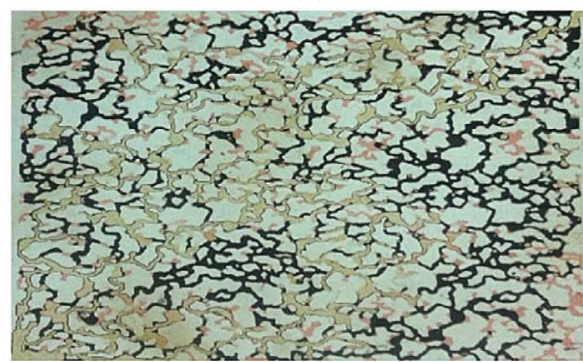

(d)

Fig. 5. Fluids transport pattern at four dimensionless times during bacteria solution injection (a) $t_{\mathrm{D}}=0,(\mathrm{~b}) t_{\mathrm{D}}=0.29$, (c) $t_{\mathrm{D}}=0.64$, and $(\mathrm{d}) t_{\mathrm{D}}=1$. The white and black represent the bacteria solution and oil phases, respectively.

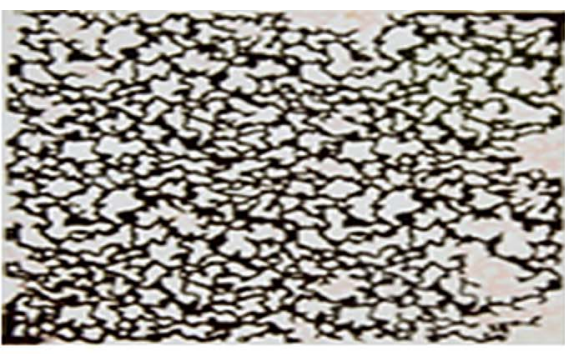

(a)

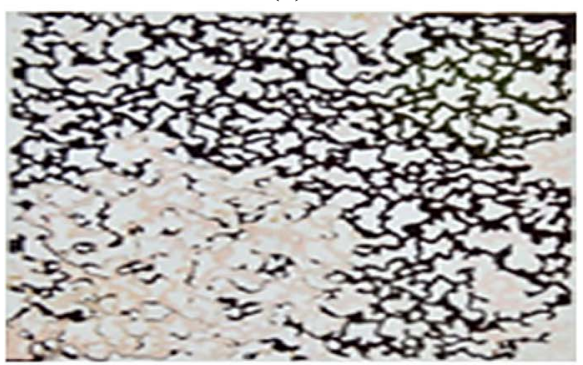

(c)

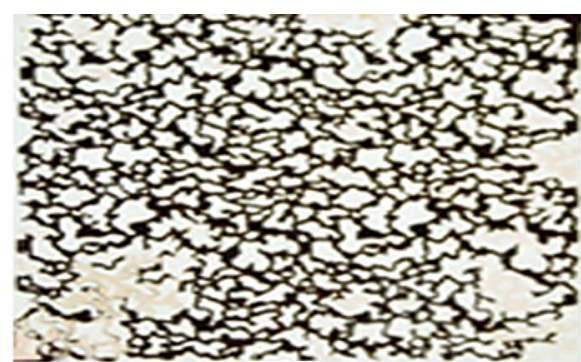

(b)

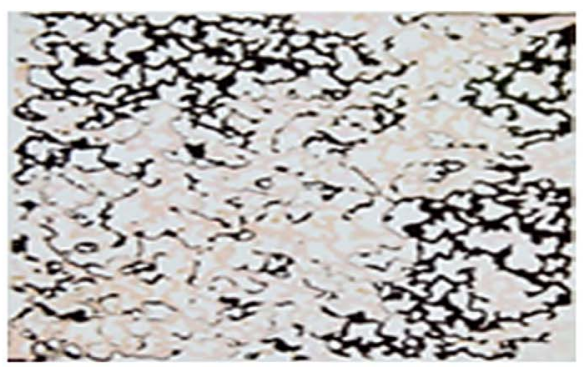

(d)

Fig. 6. Fluids transport pattern at four dimensionless times during water injection (a) $t_{\mathrm{D}}=0$, (b) $t_{\mathrm{D}}=0.29$, (c) $t_{\mathrm{D}}=0.64$, and (d) $t_{\mathrm{D}}=1$. The pink and black represent the water and oil phases, respectively.

\subsection{Effect of plugging mechanism on the displacement process}

In this section, we investigate selective plugging effects on the two-phase flow efficiency through six different models. Selective plugging is modeled by partially blocking some of the pores/throats. Simulation of selective plugging during MEOR is performed by adding some circular and linear-shape modules in pores/throats. Circular-shape module represents adsorption and plugging of hydrophobic bacteria cells which could cause "log jam" effect when passing through low-diameter pores/throats [30]. Linear-shape modules illustrate participation of bacteria-oil secondary products in the routes which form a thin film layer in the routs' wall [30]. Plugging modules used here cannot completely block the fluid flow due to the fact that "log jams" of the cells formed in this process are still permeable and they would not reduce the permeability to zero. 


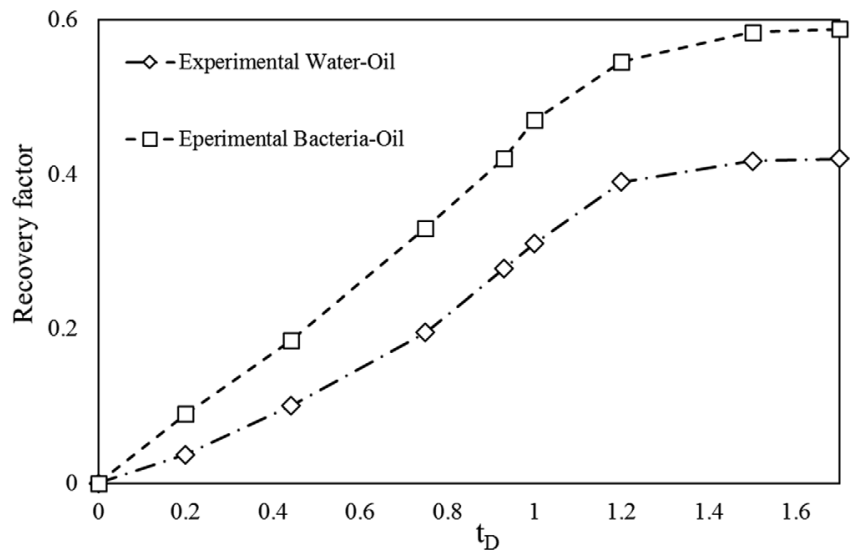

Fig. 7. Oil recovery factor as a function of dimensionless time during the water and bacteria solution injection.

This happens when increased pressure dislodges the plugging capillaries by shearing some of the cells [33]. Considering the obtained results of the first case (wateroil displacement without plugging) and the pore/throats' sizes, all of the potential pores and throats with the small radii (less than $0.1 \mathrm{~mm}$ diameter) are selected for plugging modeling. In model No 2, throats number 1, 6, and 10 are plugged as specified in Figure 3c. The linear plug is placed in the main diameter route and side routes. Figure 10 shows the distribution of the used plugging modules in model No 2 in a magnified view.

Figure 11 demonstrates the fluid distributions at six different dimensionless times for model No 2. The initial state of the fluids is shown in Figure 11a. Through water invasion, the oil phase is expelled from the outlet (Fig. 11b). One can see that instabilities take placed in the form of two wide forward and lateral moving fronts of the displacing phase (Fig. 11c). Having plugging modules in the high permeability zones of the medium (throats number 1, 6, 10 in Fig. 3c) caused a high-pressure difference in the porous media and consequently, oil is trapped in the high permeability zone located in the middle of the domain (Figs. 11d and 13a). Figure 11e shows that the two fronts have progressed and then water phase bridges between the adjacent pores and the interface coalesce occurred. It can be observed that the primary breakthrough took place by a finger proceeded to the top of the medium (Figs. 11f and 13b). Taking into account the model No 2 flow pattern, it can be deduced that by blocking high permeability zone at the main diameter pathway, bacteria solution displaces the oil of the side routes near the main diameter having smaller pores/throats and the least resistive force. This plugging caused $52 \%$ of the matrix oil to be recovered at the end of the process. Figure 12 shows a zoom-in view of the mesh distribution of model No 2 at $t_{\mathrm{D}}=1.33$. Flat, concave, and convex interfaces can be observed, which is a result of a complex interplay between the contact angle and pore angularity. Pressure and velocity fields at $t_{\mathrm{D}}=0.5$ (corresponding to Fig. 11d) for the model No 2 are presented in Figure 13.

Stabilized fluid distributions for different models No 3-7 are shown in Figure 14. Figure 14a shows the fluids distribution at the steady-state for model No 2, which was discussed before in detail. In model No 3, circular-shape modules are placed in pores/throats No 1, 2, 10 and linear-shape modules are distributed in the model. As shown in Figure 14b, water flows through the bottom-right side of the matrix, and viscous force is no longer able to dominate resistive force in the upper side of the matrix. Putting plugging modules in the main diameter traps most of the remaining oil in the middle and upper side of the matrix. Model No 3 had the least breakthrough time $(t=1.2 \mathrm{~s})$. Having the lowest breakthrough time among all models

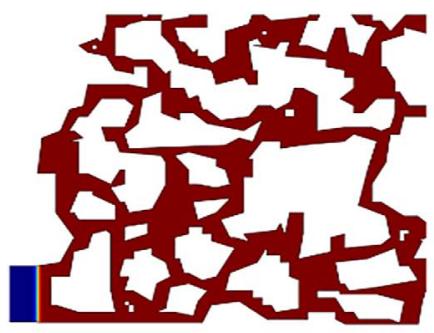

(a)

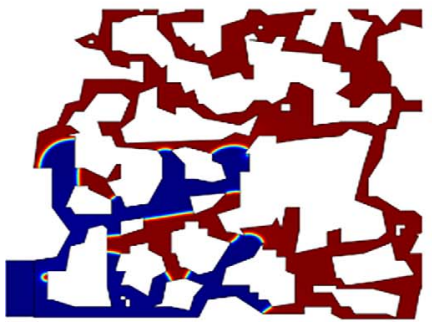

(d)

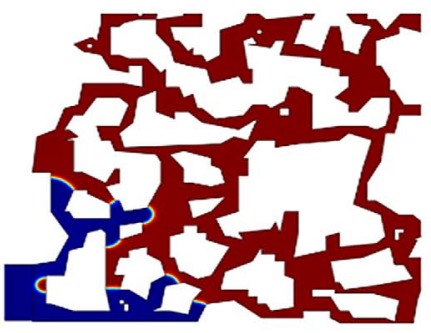

(b)

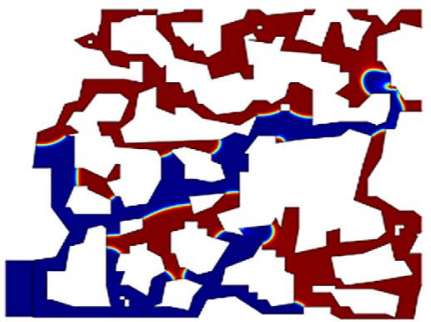

(e)

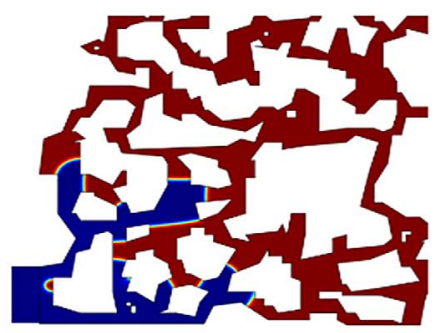

(c)

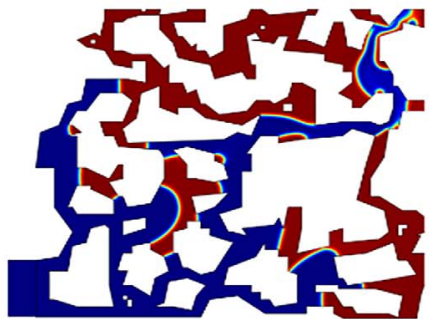

(f)

Fig. 8. Fluids transport pattern at six dimensionless times during water invasion (a) $t_{\mathrm{D}}=0$, (b) $t_{\mathrm{D}}=0.28,(\mathrm{c}) t_{\mathrm{D}}=0.42,(\mathrm{~d}) t_{\mathrm{D}}=0.57$, (e) $t_{\mathrm{D}}=0.71$, and (f) $t_{\mathrm{D}}=1$. 


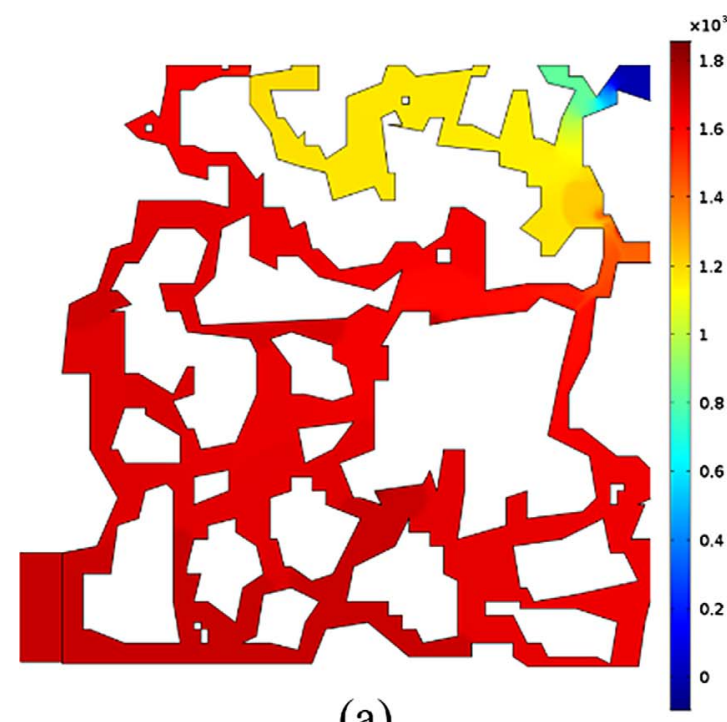

(a)

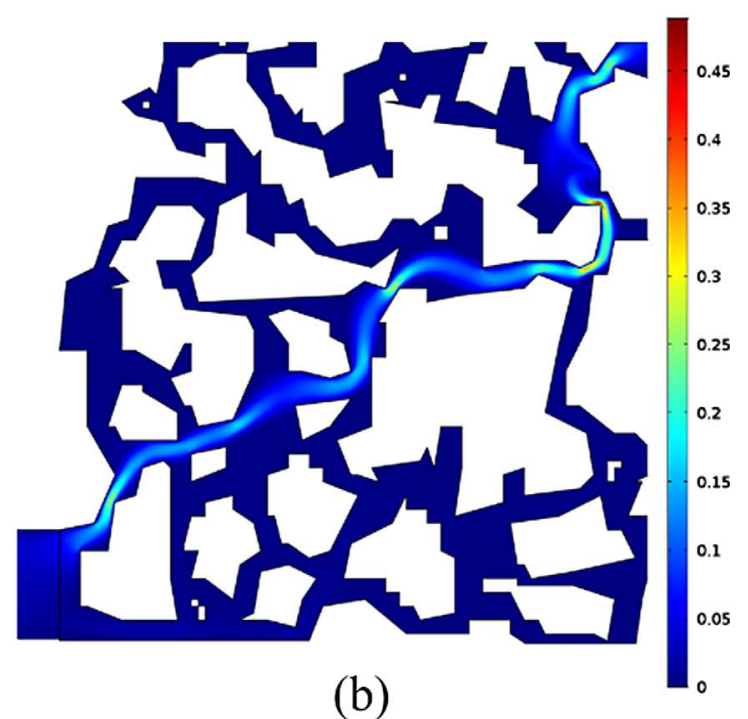

(b)

Fig. 9. (a) Pressure (Pa) and (b) velocity $(\mathrm{m} / \mathrm{s})$ distribution profiles at $t_{\mathrm{D}}=0.71(t=1 \mathrm{~s})$ for the model No 1 .

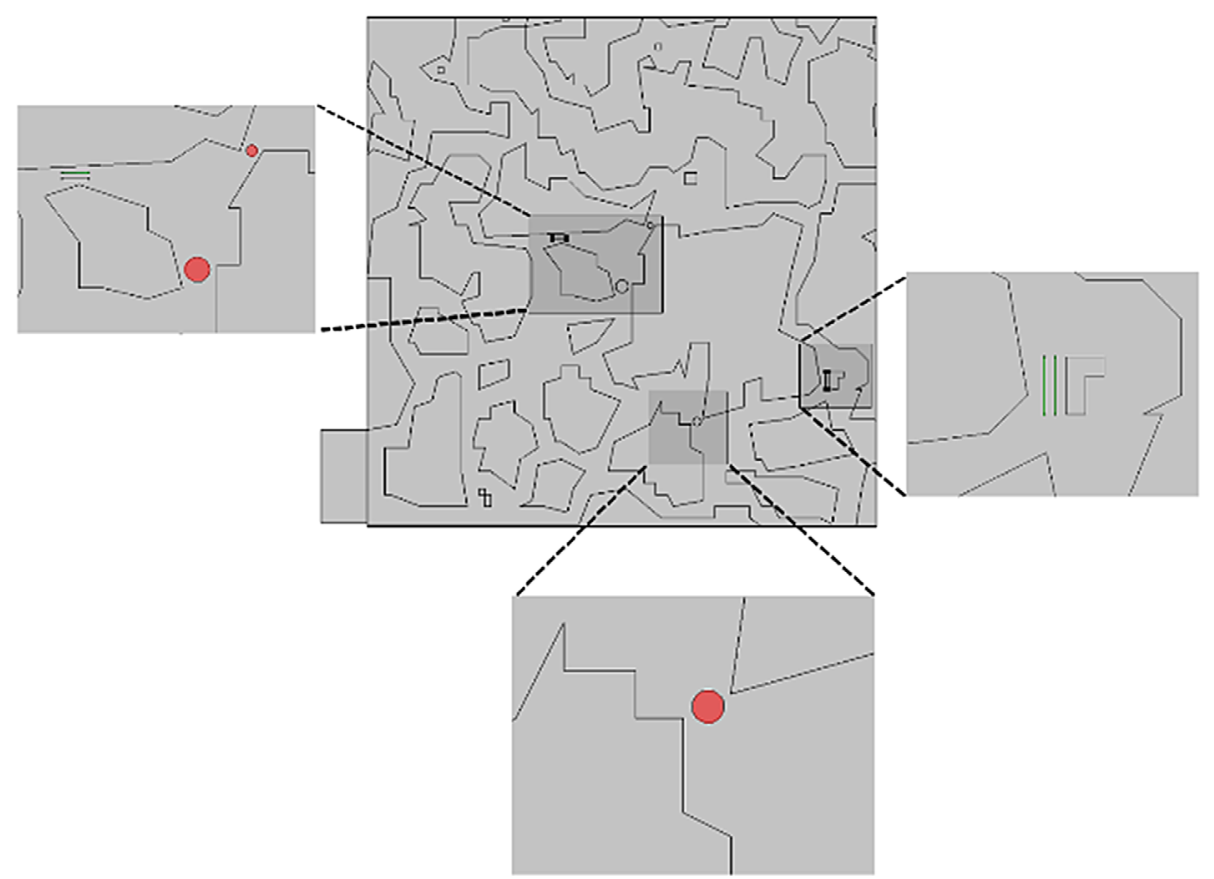

Fig. 10. Plugging modules distribution used in the model No 2. Circular and linear shape modules are specified with red and green colors, respectively.

caused the least oil recovery factor as well. By comparing models No 2 and 3, it could be deduced that the bottom side of the matrix is preferable than the top side of the matrix for displacing phase to flow, and the only possible way for sweeping the remaining oil in the top side of the matrix is plugging both middle and bottom side of the matrix.

In model No 4 (Fig. 14c), pores/throats No 1, 2, 5, specified in Figure 3c, are blocked with circular modules, while linear modules are placed in the bottom side of the matrix. Despite plugging some routes of the matrix which are located in the middle and upper side of the domain, displacing phase flows through the top side of the matrix; it reaches outlet through top side route adjacent to the diagonal pathway. The predominance of the top side route in this model is probably caused by plugging pore No 5 because in this area bottom side of the matrix intersects with the top and middle side. We can consider this pore as a critical point in which plugging phenomenon could change the swept zone. Water breakthrough occurred at $t=1.6 \mathrm{~s}$ in this model. 


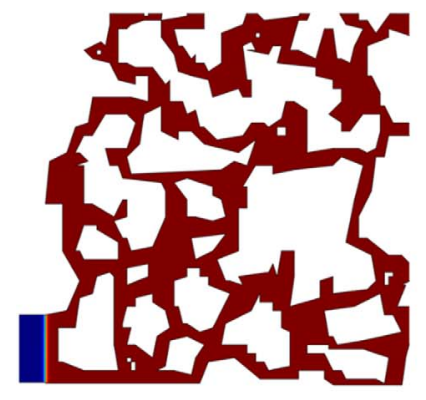

(a)

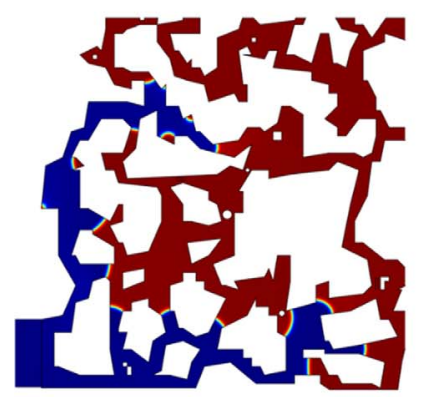

(d)

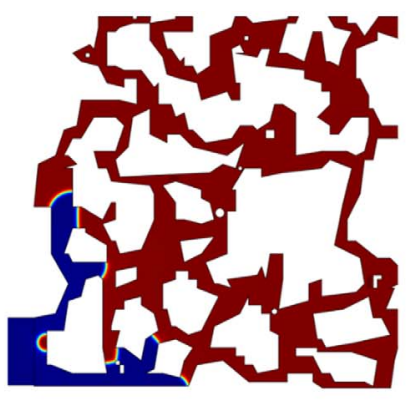

(b)

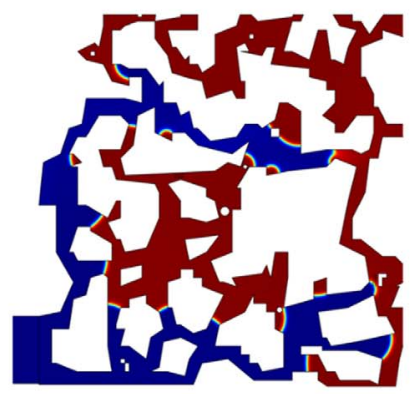

(e)

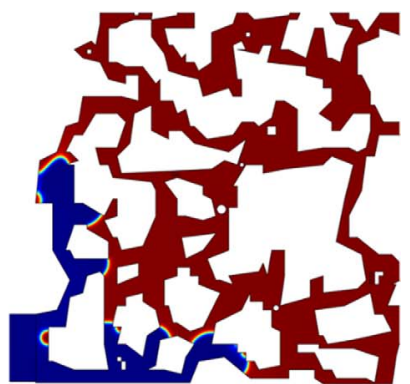

(c)

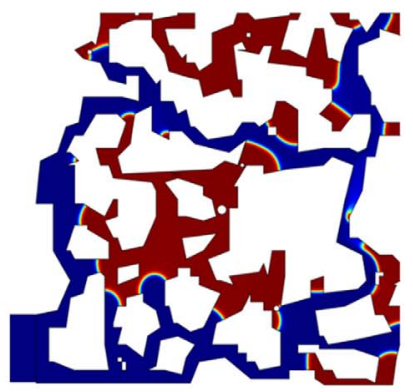

(f)

Fig. 11. Fluids transport pattern at six dimensionless times from model No 2 (a) $t_{\mathrm{D}}=0$, (b) $t_{\mathrm{D}}=0.25,(\mathrm{c}) t_{\mathrm{D}}=0.375(\mathrm{~d}), t_{\mathrm{D}}=0.5$, (e) $t_{\mathrm{D}}=0.75$, and (f) $t_{\mathrm{D}}=1$.

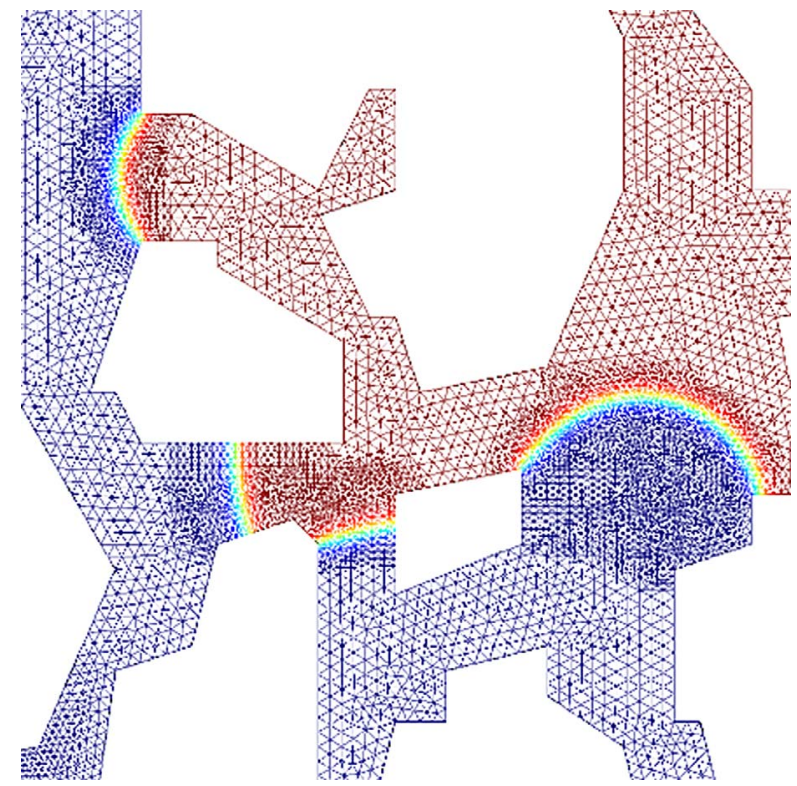

Fig. 12. Triangular mesh generated by adaptive mesh refinement with interfacial refinement in an enlarged section for model No 2.

In model No 5 (Fig. 14d), pores/throats No 1, 3, 4 are blocked by circular modules and linear modules are placed in the main diameter routes. In this model, two plugging modules are set in the diagonal middle pathway and adjacent smaller pores. The distance between the circular module used in throat No 5 and the inlet point is longer than two other circular modules used in the middle part. Despite the more resistive pressure the displacing fluid faces behind the throat No 5, water phase exits through the bottom side of the matrix. The aforementioned set of plugging illustrates that the quantity of plugging modules has a significant influence on the breakthrough time. In this model, breakthrough time increased to $3.3 \mathrm{~s}$ due to increasing the resistive pressure in every porous path.

Hitherto, we observed that blocking central routes and pores could make the flow transport inside routes considering previous models. But bacterial transport and growth actually differ in real microbial recovery cases. Hydrophobic bacteria cells gradually participate and attach to the oil as they move through the porous routes over time. A single line plugging module placed perpendicular to the fluid flow direction is used to represent gradual participation and attachment of the bacteria. Using this module, fluid can still flow through the barrier hardly. By passing bacteria solution, new plugging may create in different locations and the size of a created plugs might change over the time, it is almost impossible to reach a precise numerical model for simulating plugging formation.

In model No 6 (Fig. 14e), three single line plugging modules are used in throats No 1, 6, 13, and one circular plugging module is used in throat No 8. The high viscous force existed in the inlet area makes the flow sweep the trapped oil behind the plug. Parallel plugging is used in the main diameter and side routes. At the final stage of the simulation, some oil is trapped in the top and bottom part of the matrix (Fig. 14e). Breakthrough time was about $1.4 \mathrm{~s}$. 


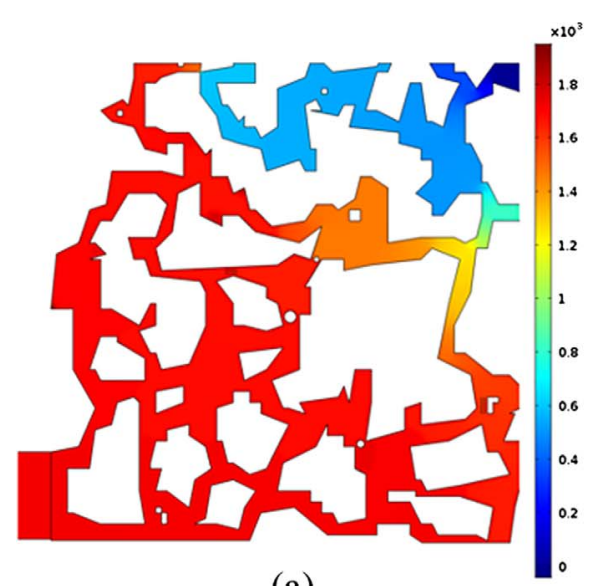

(a)

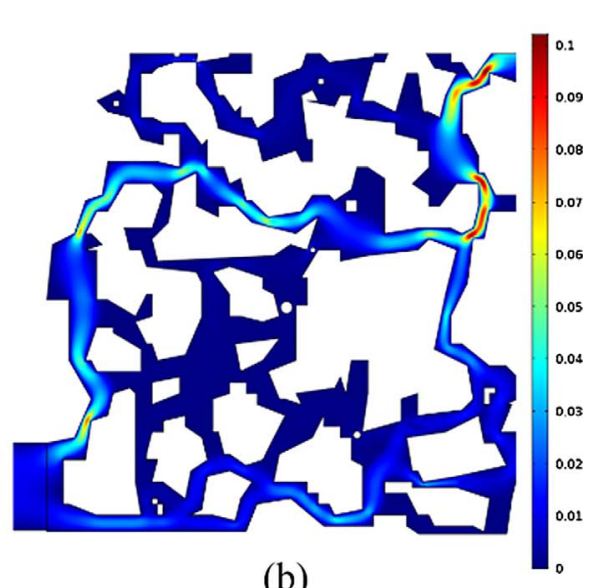

(b)

Fig. 13. (a) Pressure (Pa) and (b) velocity $(\mathrm{m} / \mathrm{s})$ distribution profiles at $t_{\mathrm{D}}=0.5$ for the model No 2 .

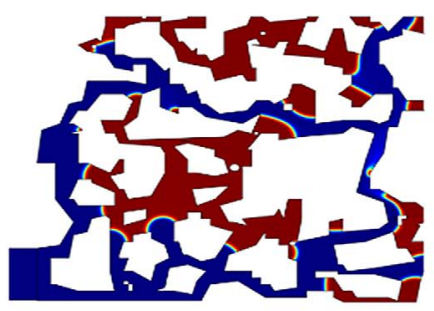

(a)

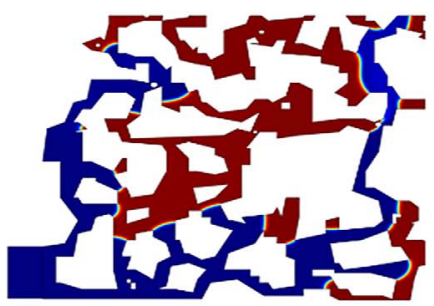

(d)

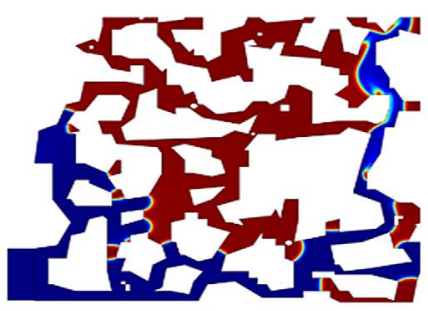

(b)

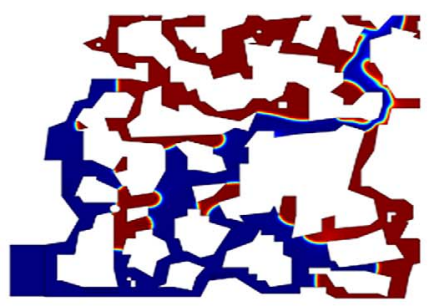

(e)

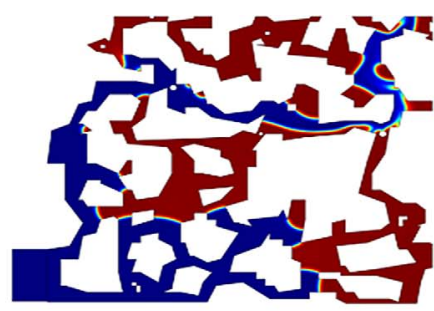

(c)

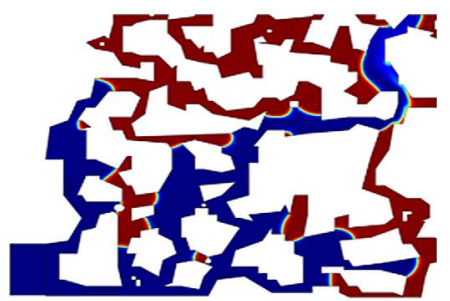

(f)

Fig. 14. Snapshots of stabilized fluid distributions for different models (a) model No 2, (b) model No 3, (c) model No 4, (d) model No 5 , (e) model No 6, and (f) model No 7.

In model No 7 (Fig. 14f), two additional circular modules are placed in the entry. Throats No 1 and 6 are blocked by single line modules and throats No 7,8 , and 9 are blocked by circular modules. This model has the highest recovery factor among other models (almost 0.54). Despite the existence of a few plugging modules in the domain, the flow pattern of this model becomes similar to the model No 1's one.

Figure 15 indicates the oil recovery as a function of dimensionless time during the displacement process for different models. As can be seen, the water-oil displacement model has an ultimate oil recovery of $49 \%$. The model No 3 recovered about $40 \%$ of the matrix oil after stabilization. However, almost $50 \%$ of the matrix oil is recovered in the other models. A possible reason for this insignificant difference can be the small dimension of the domain.
As discussed in this section, each set of plugging lead to a unique flow pattern and has a specific effect on the ultimate oil recovery.

A summary of different scenarios including plugging characteristics, porosity, permeability, and final recovery factor is presented in Table 2. It is known that porosity and permeability be changed after selective plugging. It is expected that a small change of porosity due to the clogging may lead to a variation in the permeability. To investigate this, porosity and permeability of different models were calculated, and it was observed that selective plugging lowered porosity in all models. Comparison of model No 1 and 7 reveals the key role of the pore structure on the oil recovery, even when the porosity and permeability are almost equal. Model No 5 has the lowest permeability, which led to the highest breakthrough time. Additionally, comparison of 


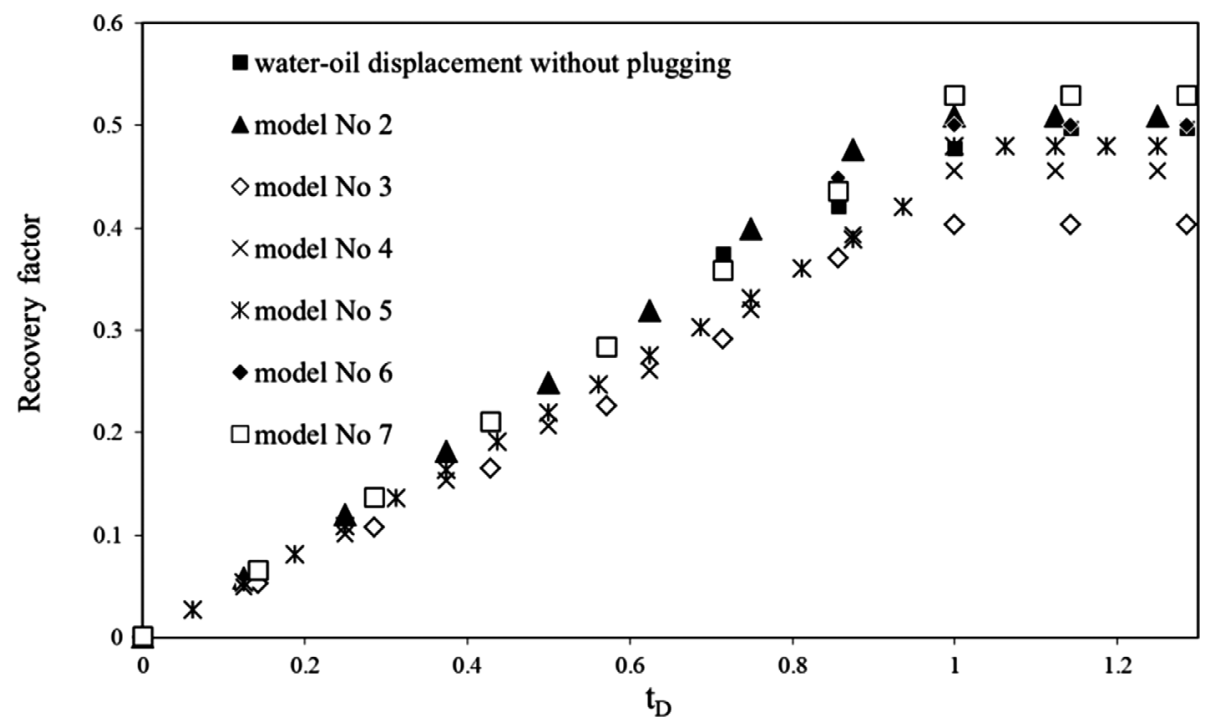

Fig. 15. Oil recovery factor as a function of dimensionless time for different models.

Table 2. Summary of input, output, porosity and permeability of different models.

\begin{tabular}{llccc}
\hline Model No & Plugging modules input & Porosity $(\%)$ & $\begin{array}{c}\text { Permeability } \\
\text { (Darcy) }\end{array}$ & $\begin{array}{c}\text { Final recovery } \\
\text { factor }(\%)\end{array}$ \\
\hline 1 & No plugging & 39.94 & 2.00 & 49 \\
2 & Throats number 1, 6,10 & 39.87 & 1.86 & 52 \\
3 & Throats number 1, 2, 10 & 39.88 & 1.80 & 39 \\
4 & Throats number 1, 2, 5 & 39.88 & 1.74 & 45 \\
5 & Throats number 1, 3, 4 & 39.89 & 1.11 & 46.5 \\
7 & Throats number 1, 6, 8, 13 & 39.89 & 1.99 & 49 \\
\hline
\end{tabular}

model No 5 and 7 shows that a small change of porosity, due to the clogging, can lead to a significant variation in the permeability.

\section{Conclusion}

This work studies the dynamics of bacteria solution injection into an oil-saturated porous media both experimentally and numerically, where selective plugging acts as the governing mechanism. In the experimental section, a 3D heterogeneous pattern analogous to a real dolomite rock section was used as the porous medium. The medium was initially saturated with the oil and connate water. Bacteria solution comprising Acinetobacter strain RAG-1 active cells mixed with limited nutrient distilled water was selected to be injected. Comparing water and bacteria solution injection results demonstrated the additional oil recovery in bacteria solution injection tests. Locations of pore plugging were determined by comparing water and bacteria solution injection, as the input for the models. To simulate this process, a finite element solver (COMSOL Multiphysics) is used to solve the governing equations. Diffusive interface method coupled with Navier-Stokes equations are the principles for numerical analysis. The same heterogeneous geometry is employed in the numerical section as the computational domain. Different sensitivity studies were performed to critically study the impact of the selective plugging mechanism on the displacement process. In the modeling part, the plugging mechanism for seven different models was investigated. In the first model, water-oil two-phase flow having non-plugging was selected as the base case. It was observed that displacing fluid takes the diagonal pathway as the most favorable route to go through. Considering models, No 2, and 3, it was shown that as the middle part of the diagonal pathway of the matrix was plugged, it resulted in oil trapping in the middle of the domain and consequently the least recovery efficiency compared to other models. It was also concluded that after plugging the intermediate zone of the matrix, displacing fluid prefer the bottom side of the media to sweep and consequently a major part of the oil in place is trapped in top and middle of the model. In model No 4, it was illustrated that the main diameter pathway could be still the preferable route after plugging. Model No 5 indicates that the 
number of plugs occurring in the medium could significantly affect the breakthrough time. In the last two models No 6 , and 7 , it was tried to model gradual precipitation and real bacteria cell plugging formation behavior. Finally, it was figured out that adjacent plugs to the inlet caused flow patterns similar to the non-plug model, and higher oil recovery factor than the models with farther plugs from the inlet. It is shown that finding a way to control bacteria selective plugging in the porous media can lead to higher recovery factors. The obtained results prove that the diffusive interface method can accurately model the selective plugging when it is the main mechanism of the enhanced oil recovery and this method can resolve the deficiency of Darcy's law in modeling such cases.

\section{References}

1 Bera A., Mandal A. (2015) Microemulsions: A novel approach to enhanced oil recovery: A review, J. Pet. Explor. Prod. Technol. 5, 3, 255-268. doi: 10.1007/s13202-014-0139-5.

2 Geetha S., Banat I.M., Joshi S.J. (2018) Biosurfactants: Production and potential applications in Microbial Enhanced Oil Recovery (MEOR), Biocatal. Agric. Biotechnol. 14, 23-32. doi: 10.1016/j.bcab.2018.01.010.

3 Patel J., Borgohain S., Kumar M., Rangarajan V., Somasundaran P., Sen R. (2015) Recent developments in microbial enhanced oil recovery, Renew. Sustain. Energy Rev. 52, 1539-1558. doi: 10.1016/j.rser.2015.07.135.

4 Muggeridge A., Cockin A., Webb K., Frampton H., Collins I., Moulds T., Salino P. (2014) Recovery rates, enhanced oil recovery and technological limits, Phil. Trans. R. Soc. A 372, 2006, 20120320. doi: 10.1098/rsta.2012.0320.

5 Amiri H.A., Hamouda A. (2014) Pore-scale modeling of nonisothermal two phase flow in 2D porous media: Influences of viscosity, capillarity, wettability and heterogeneity, Int. J. Multiphase Flow 61, 14-27. doi: 10.1016/j.ijmultiphaseflow. 2014.01.001.

6 Salehi M., Johnson S.J., Liang J.-T. (2008) Mechanistic study of wettability alteration using surfactants with applications in naturally fractured reservoirs, Langmuir 24, 24, 14099-14107. doi: 10.1021/la802464u.

7 Sun S., Luo Y., Cao S., Li W., Zhang Z., Jiang L., Dong H., Yu L., Wu W.M. (2013) Construction and evaluation of an exopolysaccharide-producing engineered bacterial strain by protoplast fusion for microbial enhanced oil recovery, Bioresour. Technol. 144, 44-49. doi: 10.1016/j.biortech.2013.06. 098.

8 Brown L.R. (2010) Microbial enhanced oil recovery (MEOR), Curr. Opin. Microbiol. 13, 3, 316-320. doi: 10.1016/j.mib.2010.01.011.

9 Lazar I., Petrisor I., Yen T. (2007) Microbial enhanced oil recovery (MEOR), Pet. Sci. Technol. 25, 11, 1353-1366. doi: 10.1080/10916460701287714.

10 Armstrong R.T., Wildenschild D., Bay B.K. (2015) The effect of pore morphology on microbial enhanced oil recovery, J. Pet. Sci. Eng. 130, 16-25. doi: 10.1016/j.petrol.2015. 03.010 .

11 Dhanarajan G., Rangarajan V., Bandi C., Dixit A., Das S., Ale K., Sen R. (2017) Biosurfactant-biopolymer driven microbial enhanced oil recovery (MEOR) and its optimization by an ANN-GA hybrid technique, J. Biotechnol. 256, 46-56. doi: 10.1016/j.jbiotec.2017.05.007.

12 Hajibagheri F., Hashemi A., Lashkarbolooki M., Ayatollahi S. (2018) Investigating the synergic effects of chemical surfactant (SDBS) and biosurfactant produced by bacterium (Enterobacter cloacae) on IFT reduction and wettability alteration during MEOR process, J. Mol. Liq. 256, 277-285. doi: 10.1016/j.molliq.2018.02.020.

13 Sarafzadeh P., Hezave A.Z., Mohammadi S., Niazi A., Ayatollahi S. (2014) Modification of rock/fluid and fluid/ fluid interfaces during MEOR processes, using two biosurfactant producing strains of Bacillus stearothermophilus SUCPM\# 14 and Enterobacter cloacae: A mechanistic study, Colloids Surf. B 117, 457-465. doi: 10.1016/ j.colsurfb.2013.12.002.

14 Al-Sulaimani H., Joshi S., Al-Wahaibi Y., Al-Bahry S., Elshafie A., Al-Bemani A. (2011) Microbial biotechnology for enhancing oil recovery: Current developments and future prospects, Biotechnol. Bioinf. Bioeng. 1, 2, 147-158.

15 Mohammed M., Babadagli T. (2015) Wettability alteration: A comprehensive review of materials/methods and testing the selected ones on heavy-oil containing oil-wet systems, Adv. Colloid Interface Sci. 220, 54-77. doi: $10.1016 /$ j.cis.2015.02.006.

16 Sen R. (2008) Biotechnology in petroleum recovery: The microbial EOR, Prog. Energy Combust. Sci. 34, 6, 714-724. doi: 10.1016/j.pecs.2008.05.001.

17 Rokhforouz M.R., Amiri H.A. (2017) Pore-level influence of wettability on counter-current spontaneous imbibition, 79th EAGE Conference and Exhibition, Paris, France, 12-15 June 2017. doi: 10.3997/2214-4609.201701510.

18 Morrow N.R., Mason G. (2001) Recovery of oil by spontaneous imbibition, Curr. Opin. Colloid Interface Sci. 6, 4, 321-337. doi: 10.1016/S1359-0294(01)00100-5.

19 Mason G., Morrow N.R. (2013) Developments in spontaneous imbibition and possibilities for future work, J. Pet. Sci. Eng. 110, 268-293. doi: 10.1016/j.petrol.2013.08.018.

20 Rabbani H.S., Joekar-Niasar V., Pak T., Shokri N. (2017) New insights on the complex dynamics of two-phase flow in porous media under intermediate-wet conditions, Sci. Rep. 7 , 4584. doi: 10.1038/s41598-017-04545-4.

21 Erfani H., Joekar-Niasar V., Farajzadeh R. (2019) Impact of micro-heterogeneity on upscaling reactive transport in geothermal energy, ACS Earth Space Chem. 3, 9, 20452057. doi: 10.1021/acsearthspacechem.9b00056.

22 Erfani Gahrooei H.R., Ghazanfari M.H., Karimi Malekabadi F. (2018) Wettability alteration of reservoir rocks to gas wetting condition: A comparative study, Can. J. Chem. Eng. 96, 4, 997-1004. doi: 10.1002/cjce.23023.

23 Hassanpouryouzband A., Yang J., Tohidi B., Chuvilin E., Istomin V., Bukhanov B., Cheremisin A. (2018) $\mathrm{CO}_{2}$ capture by injection of flue gas or $\mathrm{CO}_{2}-\mathrm{N}_{2}$ mixtures into hydrate reservoirs: Dependence of $\mathrm{CO}_{2}$ capture efficiency on gas hydrate reservoir conditions, Environ. Sci. Technol. 52, 7, 4324-4330. doi: 10.1021/acs.est.7b05784.

24 Hassanpouryouzband A., Farahani M.V., Yang J., Tohidi B., Chuvilin E., Istomin V., Bukhanov B. (2019) Solubility of flue gas or carbon dioxide-nitrogen gas mixtures in water and aqueous solutions of salts: Experimental measurement and thermodynamic modeling, Ind. Eng. Chem. Res. 58, 8, 3377-3394. doi: 10.1021/acs.iecr.8b04352. 
25 Kowalewski E., Rueslåtten I., Steen K., Bødtker G., Torsæter O. (2006) Microbial improved oil recoveryBacterial induced wettability and interfacial tension effects on oil production, J. Petrol. Sci. Eng. 52, 1, 275-286. doi: 10.1016/j.petrol.2006.03.011.

26 Darvishi P., Ayatollahi S., Roostaei A.R. (2015) Microbial enhanced oil recovery, wettability alteration and interfacial tension reduction by an Efficient Bacterial Consortium, ERCPPI-2, J. Oil. Gas. Petrochem. Technol. 2, 27-42. doi: 10.22034/jogpt.2015.9721.

27 Karimi M., Mahmoodi M., Niazi A., Al-Wahaibi Y., Ayatollahi S. (2012) Investigating wettability alteration during MEOR process, a micro/macro scale analysis, Colloids Surf. B 95, 129-136. doi: 10.1016/j.colsurfb.2012.02.035.

28 Chisholm J., Kashikar S., Knapp R., Mclnerney M., Menzies D., Silfanus N. (1990) Microbial enhanced oil recovery: Interfacial tension and gas-induced relative permeability effects, SPE Annual Technical Conference and Exhibition, Society of Petroleum Engineers. doi: 10.2118/20481-ms.

29 Arismendi Florez J.J., Ferrari J.V., Michelon M., Ulsen C. (2019) Construction of synthetic carbonate plugs: A review and some recent developments, Oil Gas Sci. Technol. - Rev. IFP Energies nouvelles 74, 29. doi: 10.2516/ogst/2019001.

30 Jack T., Shaw J., Wardlaw N., Costerton J. (1989) Microbial plugging in enhanced oil recovery, Dev. Petrol. Sci. 22, 125-149. doi: 10.1016/s0376-7361(09)70095-0.

31 Afrapoli M.S., Alipour S., Torsaeter O. (2011) Fundamental study of pore scale mechanisms in microbial improved oil recovery processes, Transp. Porous Media 90, 3, 949-964. doi: $10.1007 / \mathrm{s} 11242-011-9825-7$.

32 Armstrong R.T., Wildenschild D. (2012) Investigating the pore-scale mechanisms of microbial enhanced oil recovery, J. Pet. Sci. Eng. 94, 155-164. doi: 10.1016/j.petrol.2012.06. 031.

33 Kalish P., Stewart J., Rogers W., Bennett E. (1964) The effect of bacteria on sandstone permeability, J. Pet. Technol. 16, 07, 805-814. doi: 10.2118/579-pa.

34 Suthar H., Hingurao K., Desai A., Nerurkar A. (2009) Selective plugging strategy-based microbial-enhanced oil recovery using Bacillus licheniformis TT33, J. Microbiol. Biotechnol. 19, 10, 1230-1237.

35 Stewart T.L., Scott Fogler H. (2002) Pore-scale investigation of biomass plug development and propagation in porous media, Biotechnol. Bioeng. 77, 5, 577-588. doi: $10.1002 /$ bit.10044.

36 Karadimitriou N., Hassanizadeh S. (2012) A review of micromodels and their use in two-phase flow studies, Vadose Zone J. 11, 3. doi: 10.2136/vzj2011.0072.

37 Zhang C., Oostrom M., Wietsma T.W., Grate J.W., Warner M.G. (2011) Influence of viscous and capillary forces on immiscible fluid displacement: Pore-scale experimental study in a water-wet micromodel demonstrating viscous and capillary fingering, Energy Fuels 25, 8, 3493-3505. doi: $10.1021 /$ ef101732k.

38 Lenormand R., Touboul E., Zarcone C. (1988) Numerical models and experiments on immiscible displacements in porous media, J. Fluid Mech. 189, 165-187. doi: 10.1017/ s0022112088000953.

39 Fan Y., Gao K., Chen J., Li W., Zhang Y. (2018) Low-cost PMMA-based microfluidics for the visualization of enhanced oil recovery, Oil Gas Sci. Technol. - Rev. IFP Energies nouvelles 73, 26. doi: 10.2516/ogst/2018026.
40 Khan H.A., Gbosi A., Britton L.N., Bryant S.L. (2008) Mechanistic models of microbe growth in heterogeneous porous media, SPE Symposium on Improved Oil Recovery, Society of Petroleum Engineers. doi: 10.2118/113462-ms.

41 Raeesi B., Piri M. (2009) The effects of wettability and trapping on relationships between interfacial area, capillary pressure and saturation in porous media: A pore-scale network modeling approach, J. Hydrol. 376, 3-4, 337-352. doi: 10.1016/j.jhydrol.2009.07.060.

42 Gahrooei H.R.E., Ghazanfari M.H. (2017) Application of a water based nanofluid for wettability alteration of sandstone reservoir rocks to preferentially gas wetting condition, J. Mol. Liq. 232, 351-360. doi: 10.1016/j.molliq.2017.02. 097.

43 Li J., Jiang H., Wang C., Zhao Y., Gao Y., Pei Y., Wang C., Dong H. (2017) Pore-scale investigation of microscopic remaining oil variation characteristics in water-wet sandstone using CT scanning, J. Nat. Gas Sci. Eng. 48, 36-45. doi: 10.1016/j.jngse.2017.04.003.

44 Blunt M., King P. (1991) Relative permeabilities from twoand three-dimensional pore-scale network modelling, Transp. Porous Media 6, 4, 407-433. doi: 10.1007/bf00136349.

45 Piri M., Blunt M.J. (2005) Three-dimensional mixed-wet random pore-scale network modeling of two-and three-phase flow in porous media. I. Model description, Phys. Rev. E 71, 2, 026301. doi: 10.1103/physreve.71.026301.

46 Raeini A.Q., Blunt M.J., Bijeljic B. (2012) Modelling twophase flow in porous media at the pore scale using the volume-of-fluid method, J. Comput. Phys. 231, 17, 56535668. doi: 10.1016/j.jcp.2012.04.011.

47 Bandara U.C., Tartakovsky A.M., Palmer B.J. (2011) Porescale study of capillary trapping mechanism during $\mathrm{CO}_{2}$ injection in geological formations, Int. J. Greenhouse Gas Control 5, 6, 1566-1577. doi: 10.1016/j.ijggc.2011.08.014.

48 Tartakovsky A.M., Meakin P. (2006) Pore scale modeling of immiscible and miscible fluid flows using smoothed particle hydrodynamics, Adv. Water Resour. 29, 10, 1464-1478. doi: 10.1016/j.advwatres.2005.11.014.

49 Huang H., Huang J.-J., Lu X.-Y. (2014) Study of immiscible displacements in porous media using a color-gradient-based multiphase lattice Boltzmann method, Comput. Fluids 93, 164-172. doi: 10.1016/j.compfluid.2014.01.025.

50 Zhang J. (2011) Lattice Boltzmann method for microfluidics: Models and applications, Microfluid. Nanofluid. 10, 1, 1-28. doi: 10.1007/s10404-010-0624-1.

51 Krol M.M., Mumford K.G., Johnson R.L., Sleep B.E. (2011) Modeling discrete gas bubble formation and mobilization during subsurface heating of contaminated zones, $A d v$. Water Resour. 34, 4, 537-549. doi: 10.1016/j.advwatres. 2011.01.010.

52 Lenormand R. (1989) Flow through porous media: Limits of fractal patterns, Proceedings of the Royal Society of London A: Mathematical, Physical and Engineering Sciences, The Royal Society. doi: 10.1098/rspa.1989.0048.

53 Ferrari A., Lunati I. (2013) Direct numerical simulations of interface dynamics to link capillary pressure and total surface energy, Adv. Water Resour. 57, 19-31. doi: 10.1016/j. advwatres.2013.03.005.

54 Shams M., Raeini A.Q., Blunt M.J., Bijeljic B. (2018) A numerical model of two-phase flow at the micro-scale using the volume-of-fluid method, J. Comput. Phys. 357, 159-182. doi: $10.1016 /$ j.jcp.2017.12.027. 
55 Sethian J.A., Smereka P. (2003) Level set methods for fluid interfaces, Annu. Rev. Fluid Mech. 35, 1, 341-372. doi: 10.1146/annurev.fluid.35.101101.161105.

56 Rokhforouz M., Akhlaghi Amiri H.A. (2017) Phase-field simulation of counter-current spontaneous imbibition in a fractured heterogeneous porous medium, Phys. Fluids 29, 6, 062104. doi: 10.1063/1.4985290.

57 Rokhforouz M., Amiri H.A. (2018) Pore-level influence of micro-fracture parameters on visco-capillary behavior of twophase displacements in porous media, Adv. Water Resour. 113, 260-271. doi: 10.1016/j.advwatres.2018.01.030.

58 Rokhforouz M., Amiri H.A. (2019) Effects of grain size and shape distribution on pore-scale numerical simulation of twophase flow in a heterogeneous porous medium, Adv. Water Resour. 124, 84-95. doi: 10.1016/j.advwatres.2018.12.008.

59 Ahmadi P., Ghandi E., Riazi M., Malayeri M.R. (2019) Experimental and CFD studies on determination of injection and production wells location considering reservoir heterogeneity and capillary number, Oil Gas Sci. Technol. - Rev. IFP Energies nouvelles 74, 4. doi: 10.2516/ogst/2018078.

60 Meakin P., Tartakovsky A.M. (2009) Modeling and simulation of pore-scale multiphase fluid flow and reactive transport in fractured and porous media, Rev. Geophys. 47, 3. doi: $10.1029 / 2008 \mathrm{rg} 000263$.

61 Amiri H.A., Hamouda A. (2013) Evaluation of level set and phase field methods in modeling two phase flow with viscosity contrast through dual-permeability porous medium, Int. J. Multiphase Flow 52, 22-34. doi: 10.1016/j.ijmultiphaseflow. 2012.12.006.

62 Basirat F., Yang Z., Niemi A. (2017) Pore-scale modeling of wettability effects on $\mathrm{CO}_{2}$-brine displacement during geological storage, Adv. Water Resour. 109, 181-195. doi: 10.1016/j.advwatres.2017.09.004.

63 Maaref S., Rokhforouz M.R., Ayatollahi S. (2017) Numerical investigation of two phase flow in micromodel porous media: Effects of wettability, heterogeneity, and viscosity, Can. J. Chem. Eng. 95, 6, 1213-1223. doi: 10.1002/cjce.22762.

64 Alpak F.O., Riviere B., Frank F. (2016) A phase-field method for the direct simulation of two-phase flows in porescale media using a non-equilibrium wetting boundary condition, Comput. Geosci. 20, 5, 881-908. doi: 10.1007/ s10596-015-9551-2.

65 Phuong K., Hanazaki S., Kakii K., Nikata T. (2012) Involvement of Acinetobacter sp. in the floc-formation in activated sludge process, J. Biotechnol. 157, 4, 505-511. doi: 10.1016/j.jbiotec.2011.09.024.

66 COMSOL Multiphysics (2012) User's Guide, Version 4.3, Comsol Inc., Stockholm, Sweden.

67 Rokhforouz M.-R., Rabbani A., Ayatollahi S., Taghikhani V. (2016) Numerical analysis of heat conduction treated with highly conductive copper oxide nanoparticles in porous media, Spec. Top. Rev. Porous Media 7, 2. doi: 10.1615/ specialtopicsrevporousmedia.2016017291.

68 Cahn J.W., Hilliard J.E. (1958) Free energy of a nonuniform system. I. Interfacial free energy, J. Chem. Phys. 28, 2, 258-267. doi: 10.1002/9781118788295.ch4.

69 Yue P., Feng J.J. (2011) Wall energy relaxation in the Cahn-Hilliard model for moving contact lines, Phys. Fluids 23, 1, 012106. doi: 10.1063/1.3541806.

70 Yue P., Zhou C., Feng J.J. (2010) Sharp-interface limit of the Cahn-Hilliard model for moving contact lines, J. Fluid Mech. 645, 279-294. doi: 10.1017/s0022112009992679. 